\title{
Impact of brief or extended extinction of a taste aversion on inhibitory associations: Evidence from summation, retardation, and preference tests
}

\author{
DOUGLAS C. BROOKS \\ Denison University, Granville, Ohio \\ and \\ JONNA L. BOWKER, JENISE E. ANDERSON, and MATTHEW I. PALMATIER \\ California State University, Fresno, California
}

\begin{abstract}
In five conditioned taste aversion experiments with rats, summation, retardation, and preference tests were used to assess the effects of extinguishing a conditioned saccharin aversion for three or nine trials. In Experiment 1, a summation test showed that saccharin aversion extinguished over nine trials reduced the aversion to a merely conditioned flavor (vinegar), whereas three saccharin extinction trials did not subsequently influence the vinegar aversion. Experiment 2 clarified that result, with unpaired controls equated on flavor exposure prior to testing; the results with those controls suggested that the flavor extinguished for nine trials produced generalization decrement during testing. In Experiment 3, the saccharin aversion reconditioned slowly after nine extinction trials, but not after three. Those results suggested the development of latent inhibition after more than three extinction trials. Preference tests comparing saccharin consumption with a concurrently available fluid (water in Experiment 4, saline in Experiment 5) showed that the preference for saccharin was greater after nine extinction trials than after three. However, saccharin preference after nine extinction trials was not greater, as compared with that for either latent inhibition controls (Experiments 4 and 5) or a control given equated exposures to saccharin and trained to drink saline at a high rate prior to testing (Experiment 5). Concerns about whether conditioned inhibition has been demonstrated in any flavor aversion procedure are discussed. Our findings help explain both successes and failures in demonstrating postextinction conditioned response recovery effects reported in the conditioned taste aversion literature, and they can be explained using a memory interference account.
\end{abstract}

Conditioned inhibition as a result of conditioned stimulus (CS) alone extinction is predicted by several conditioning theories (e.g., Hull, 1943; Konorski, 1948; Miller, Kasprow, \& Schachtman, 1986; Pavlov, 1927; Pearce \& Hall, 1980) and has been examined in a number of reports (see LoLordo \& Fairless, 1985; Mackintosh, 1983; Rescorla, 1979). Extinction of a conditioned taste aversion (CTA) may permit the extinguished flavor CS to pass commonly accepted tests for conditioned inhibition (Rescorla, 1969; see Savastano, Cole, Barnet, \& Miller, 1999; Williams, Overmier, \& LoLordo, 1992). This has been suggested by several studies. For example, Schachtman (e.g., Calton, Mitchell, \& Schachtman, 1996; Hart, Bourne, \& Schachtman, 1995) has provided evidence that a conditioned flavor simply extinguished for eight or nine

This research was supported by grants from Denison University and California State University, Fresno. We thank Todd Schachtman, Ralph Miller, and several anonymous reviewers for comments on earlier versions of this manuscript. Correspondence concerning this article should be addressed to D. C. Brooks, Department of Psychology, Denison University, Granville, OH 43023 (e-mail: brooksc@ denison.edu).

-Accepted by the previous editorial team of Ralph R. Miller. trials subsequently passes summation and retardation tests (see also Danguir \& Nicolaidis, 1977; Schachtman, Threlkeld, \& Meyer, 2000). However, in a retardation test, Hart et al. (1995, Experiment 1) did not find evidence consistent with conditioned inhibition to a flavor extinguished for only three trials. As Hart et al. and others (e.g., Bouton, 1986) have suggested, extended extinction may be needed to yield a conditioned inhibitor.

Other CTA results indicate that different amounts of extinction may differentially affect performance after extinction. For example, reinstatement has been shown to occur following three extinction trials (Schachtman, Brown, \& Miller, 1985; see also Schachtman, Gustavson, Chelonis, \& Bourne, 1992), but not following five or more such trials (Bouton, 1982; Schachtman et al., 1985). Spontaneous recovery has been shown to occur after three extinction trials (e.g., Brooks, Palmatier, Garcia, \& Johnson, 1999; Rosas \& Bouton, 1996, Experiments 1-3; cf. Kraemer \& Spear, 1992), but not after eight (Rosas \& Bouton, 1996, Experiment 4; see also Hart et al., 1995; Schachtman et al., 1985).

Various factors could account for these differences, including the amount and duration of conditioning and the 
duration of the retention interval between extinction and testing. Another possibility is that with CTA procedures such as those used in prior studies, a strong form of demonstrable inhibition (e.g., conditioned inhibition) develops only after more than approximately three extinction trials. Such a suggestion has been made (e.g., Hart et al., 1995), and some evidence for it has accumulated (e.g., Calton et al., 1996; Danguir \& Nicolaidis, 1977; Hart et al., 1995; Schachtman et al., 2000). However, to our knowledge, no direct comparisons of conditioned inhibition after different numbers of extinction trials have been conducted. Until now, only cross-experiment or cross-study comparisons could be made. For example, Hart et al. (1995) used three and nine extinction trials in different experiments. Rosas and Bouton (1996) used three and eight extinction trials in different experiments and tested for spontaneous recovery, not inhibition. Schachtman et al. (1985) assessed the effect of three or more extinction trials in the same experiment but tested for reinstatement. Furthermore, Rescorla's (1969) dual tests for conditioned inhibition have not been conducted, in any set of experiments or studies, both after three and after more than three extinction trials. Calton et al. (1996) conducted retardation and summation tests after only nine trials; Hart et al. (1995) conducted only a retardation test.

The main objective of the present study was to use different tests for conditioned inhibition after three or nine extinction trials and to compare the effects of three and nine trials in the same experiment. This allowed us also to evaluate these tests with the present designs and with respect to the results those tests have yielded in previous research (e.g., Calton et al., 1996). Each of five experiments employed groups of rats for which a conditioned saccharin aversion was extinguished for three or nine trials. After extinction in Experiments 1-3, summation and retardation tests were used. We also assessed the twobottle preference test technique (Experiments 4 and 5) used initially by Best (1975; Best, Dunn, Batson, Meachum, \& Nash, 1985) in a study of conditioned inhibition, using CTA. After A+/AX - inhibition training procedures using CTA $(\mathrm{A}=$ the drinking box, $\mathrm{X}=\mathrm{a}$ flavored solution), Best reported conditioned inhibition with such a test. In contrast, Delamater, Krause, Marlin, and LoLordo (1986) found no evidence of conditioned inhibition with preference, summation, or retardation tests after $\mathrm{A}+\mathrm{AX}$ - training. Together, these earlier findings suggest, at a minimum, that a conditioned inhibition phenomenon after $\mathrm{A}+/ \mathrm{AX}$ - training using CTA may be elusive (Delamater et al., 1986; but see Calton et al., 1996; Schachtman et al., 2000). Differences in the stimuli and procedures used by Best and Delamater might account for their conflicting results (see Delamater et al., 1986), but nevertheless, the validity of preference testing using CTA is open to question. LoLordo and Fairless (1985, p. 4) encouraged comparisons of preference, summation, and retardation tests; however, few exist (cf. Delamater et al., 1986, after A+/AX - procedures), and we know of none in which the effects of extinction are assessed. Given these circumstances, preference tests were conducted here in order to begin to evaluate their convergent validity with summation and retardation tests as a measure of inhibition after extinction. The preference tests conducted here used the same stimuli and followed the same conditioning and extinction procedures as those used for the present summation and retardation test experiments.

\section{EXPERIMENT 1}

In Experiment 1, a summation test was used. There are few clear findings of inhibition with such a test in CTA. After A+/AX - training, Delamater et al. (1986) found that the putative inhibitor failed a summation test. However, also after A+/AX - training, Best et al. (1985, Experiment 2) produced a result consistent with conditioned inhibition in a summation test. However, they did not use a new excitatory flavor in testing but, rather, used the training excitor. Following simple extinction involving nine trials, Calton et al. (1996, Experiments 2 and 3B) provided evidence of a flavor's passing a summation test. Recently, Aguado, de Brugada, and Hall (2001, Experiments 3 and 4) reported summation tests that appeared to challenge the conditioned inhibition view. They suggested preliminary evidence that Calton et al.'s summation test results may have been due to generalization decrement, rather than to conditioned inhibition. In Experiment 1, we followed Calton et al.'s procedures with nine extinction trials and, for the first time, directly compared the effect with that of only three trials. In Experiment 2, we further assessed the role of generalization decrement, using a design and procedures that had not been used previously to assess conditioned inhibition after extinction with CTA.

The design of Experiment 1 is shown in Table 1. There were four groups that received a single conditioning trial of saccharin paired with lithium chloride $(\mathrm{LiCl})$. Then Groups 9E and 9C received nine saccharin-alone extinction trials; Groups $3 \mathrm{E}$ and $3 \mathrm{C}$ received three such trials. Following the extinction phase, all four groups received conditioning with another flavor (vinegar) that was to be used as the excitatory transfer CS on the subsequent summation test. On the test, Groups 9E and 3E received a simultaneous compound of saccharin and vinegar, whereas Groups $9 \mathrm{C}$ and $3 \mathrm{C}$ received vinegar alone. With these procedures, if more than three extinction trials are necessary for the summation result, Group 9E should consume more than Group 9C, and Groups 3E and 3C should not differ.

\section{Method}

Subjects and Apparatus. The subjects were 32 naive male Wistar rats bred at California State University, Fresno (CSUF). They were approximately 90 days old and ranged in weight from 275 to $400 \mathrm{~g}$ at the start of the experiment. They were individually housed in suspended wire cages in a room maintained on a $14: 10$-h light:dark cycle; the light part of the cycle began at $0630 \mathrm{~h}$. Food was available in the home cages throughout the experiment.

A room adjacent to the colony room was used for all flavored solution presentations. It contained a table with eight stainless steel drinking boxes on it. Each box measured $19 \times 24 \times 14 \mathrm{~cm}$ and had 
Table 1

Design of Experiments 1-3

\begin{tabular}{|c|c|c|c|c|}
\hline Group & Conditioning & Extinction & & Test \\
\hline \multicolumn{5}{|c|}{ Experiment 1} \\
\hline $9 \mathrm{E}$ & Sact & 9Sac- & Vin+ & Sac \& Vin - \\
\hline $9 \mathrm{C}$ & Sac+ & 9Sac- & Vin+ & Vin - \\
\hline $3 \mathrm{E}$ & $\mathrm{Sac}+$ & $3 \mathrm{Sac}-$ & Vin+ & Sac \& Vin - \\
\hline $3 \mathrm{C}$ & Sac+ & $3 \mathrm{Sac}-$ & Vin+ & Vin- \\
\hline \multicolumn{5}{|c|}{ Experiment 2} \\
\hline $9 \mathrm{E}$ & Sact & 9Sac- & Vin+ & Sac \& Vin - \\
\hline $9 \mathrm{C}$ & Sac+ & 9Sac- & Vin+ & Vin- \\
\hline YE & $+/ \mathrm{Sac}$ & 9Sac- & Vin+ & Sac \& Vin - \\
\hline $\mathrm{YC}$ & $+/ \mathrm{Sac}$ & 9Sac- & Vin+ & Vin- \\
\hline \multicolumn{5}{|c|}{ Experiment 3} \\
\hline $9 \mathrm{E}$ & Sac+ & 9Sac- & & $\mathrm{Sac}+$; Sac- \\
\hline $9 \mathrm{C}$ & Sal+ & 9Sal- & & $\mathrm{Sac}+; \mathrm{Sac}-$ \\
\hline $3 \mathrm{E}$ & Sac+ & $3 \mathrm{Sac}-$ & & $\mathrm{Sac}+; \mathrm{Sac}-$ \\
\hline $3 \mathrm{C}$ & Sal+ & 3Sal- & & $\mathrm{Sac}+$; Sac- \\
\hline
\end{tabular}

Note- "Sac" indicates the $0.05 \%$ saccharin solution; "Sal" indicates a $1.3 \%$ saline solution; "Vin" indicates a $2 \%$ vinegar solution; "+" indicates lithium chloride; "-" indicates no US; numbers in the extinction phase refer to number of trials.

a lid with ventilation slots and a hole centered in it to accommodate a drinking tube. Illumination was provided by four $4-\mathrm{W}$ incandescent bulbs; one bulb was centered between every two boxes and was positioned approximately $50 \mathrm{~cm}$ above the lids of the boxes. A 55-dB fan provided masking noise. The target CS flavor was a $0.05 \%$ sodium saccharin (EM Science, Gibbstown, NJ) solution mixed in distilled water. An additional CS was provided by a $2 \%$ distilled white vinegar solution (Heinz, Pittsburgh, PA). In the initial conditioning phase of each experiment, illness was induced by a $0.3-\mathrm{M}$ intraperitoneal injection of $\mathrm{LiCl}$ (EM Science, Gibbstown, $\mathrm{NJ}$ ), also mixed with distilled water. $\mathrm{All} \mathrm{LiCl}$ injections were $1 \%$ of body weight. Fluids were administered at room temperature from drinking tubes constructed of 30-ml plastic syringes fitted with a stainless steel drinking spout that protruded $5 \mathrm{~cm}$ into the drinking box.

Procedure. The experiment was run on consecutive days. All the drinking sessions were $15 \mathrm{~min}$ in duration, and distilled water was used. Each rat received two drinking sessions per day; the first began at approximately $0730 \mathrm{~h}$, and the second at approximately $1630 \mathrm{~h}$ (9-h separation). The second drinking session simply involved access to water in the colony room. Hereafter, only the first drinking session will be described.

On the first 8 days, all the rats received water. On the first 2 of those days, water was given in the colony room. On the next day, all the rats received $15 \mathrm{~min}$ of exposure to the drinking boxes, during which they received no fluid, followed within $90 \mathrm{~min}$ by a waterdrinking session in the colony room. On the next 5 days, water was given in the drinking boxes. The rats were then assigned to Groups $9 \mathrm{E}, 9 \mathrm{C}, 3 \mathrm{E}$, and $3 \mathrm{C}(n \mathrm{~s}=8)$, balanced on water intake during these 8 days.

On the next day, Groups 9E and 9C received conditioning, which involved access to saccharin for $15 \mathrm{~min}$, followed within $10 \mathrm{~min}$ by an injection of $\mathrm{LiCl}$. Injections were given in the corridor outside the room that contained the drinking boxes. Immediately following the injection, each rat was placed back in its drinking box for approximately $5 \mathrm{~min}$ (with no fluids available) and was then returned to its cage in the colony room. On the day after conditioning, each rat received a recovery day on which a water-drinking session was given in the colony room. On each of the next 9 days, these groups received access to saccharin for $15 \mathrm{~min}$ in the drinking boxes without $\mathrm{LiCl}$. During the days on which Groups 9E and 9C received conditioning, the recovery day, and the first four extinction trials, Groups $3 \mathrm{E}$ and $3 \mathrm{C}$ received water in the drinking boxes. They then received the conditioning and recovery days, using the same procedures as those for the other groups. On the next 3 days (i.e., the final 3 days of extinction for Groups 9E and 9C), Groups 3E and 3C also received saccharin without $\mathrm{LiCl}$. This procedure was designed to equate the motivation to drink in all the groups at the time of testing; all four groups were tested on the same days and were placed on a schedule of two drinks per day for the same number of days prior to testing. One rat from Group 9E did not drink suff icient saccharin during conditioning (the criterion for insufficient consumption during conditioning was less than $2 \mathrm{ml}$ ), and 1 rat from Group 3C did not show evidence of extinction (the criterion for insufficient extinction was drinking less than $3 \mathrm{ml}$ on each of the first three extinction trials); the data from those rats were eliminated from the study (the resulting $n \mathrm{~s}=7$ for those groups).

On the day following the end of extinction, all the groups received conditioning with a $2 \%$ vinegar solution and $0.3 \mathrm{M}$ of $\mathrm{LiCl}$, using the same procedure as that for initial saccharin conditioning. The next day was a recovery day. The next 2 days made up the summation test. On each test day, Groups $9 \mathrm{E}$ and $3 \mathrm{E}$ received a simultaneous 50/50 compound of the vinegar and saccharin solutions (each double the original concentrations); Groups 9C and 3C received only vinegar.

In each experiment, the amount of fluid consumed was measured to the nearest milliliter and was evaluated with an analysis of variance (ANOVA). Planned comparisons were conducted using the techniques discussed by Howell (1987, pp. 431-443). The rejection criterion was always set at $p<.05$.

\section{Results and Discussion}

Figure 1 shows mean saccharin consumption for the four groups on the conditioning trial and the three or nine extinction trials. There were no differences among the groups on the conditioning trial. An extinction trials (9 vs. 3$) \times$ test condition (compound vs. vinegar alone) ANOVA revealed no significant effects and no interaction $[F \mathrm{~s}(1,26)<1.10, p \mathrm{~s}>.30]$. The groups showed similar aversions to saccharin. A trial (conditioning vs. first extinction) $\times$ extinction trials $\times$ test condition ANOVA revealed an effect of trial $[F(1,26)=373.04]$ but no other effects and no interactions $\left[F_{\mathrm{s}}(1,26)<1.36\right.$, $p$ s $>.25]$. There were also no differences among the groups during Extinction Trials 1-3; a trial $\times$ extinction trials $\times$ test condition ANOVA revealed an effect of trial $[F(1,26)=167.52]$ but no other effects and no interactions $\left(F_{\mathrm{S}}<1.98, p \mathrm{~s}>.14\right)$. The groups also did not differ on their respective final extinction trial (Trial 9 for Groups 9E and 9C, Trial 3 for Groups 3E and 3C). An extinction trials $\times$ test condition ANOVA on that trial revealed no effects or interaction $\left[F_{\mathrm{s}}(1,26)<2.53, p \mathrm{~s}>\right.$ .12]. The groups also consumed similar amounts of vinegar during the vinegar conditioning trial. An extinction trials $\times$ test condition ANOVA on that trial revealed no effects and no interaction $\left[F_{\mathrm{s}}(1,26)<2.53, p \mathrm{~s}>.12\right]$.

Figure 2 shows the results of the summation test. Group 9E drank significantly more fluid than did Group 9C. Groups 3E and 3C did not differ. An extinction trials $\times$ test condition ANOVA on the two-trial block of the test revealed an effect of test condition $[F(1,26)=5.40]$, indicating greater overall consumption of the compound. The effect of extinction trials was not significant $[F(1,26)<2.29, p>.14]$, but the interaction was $[F(1,26)=4.83]$. Comparisons revealed that Group 9E 


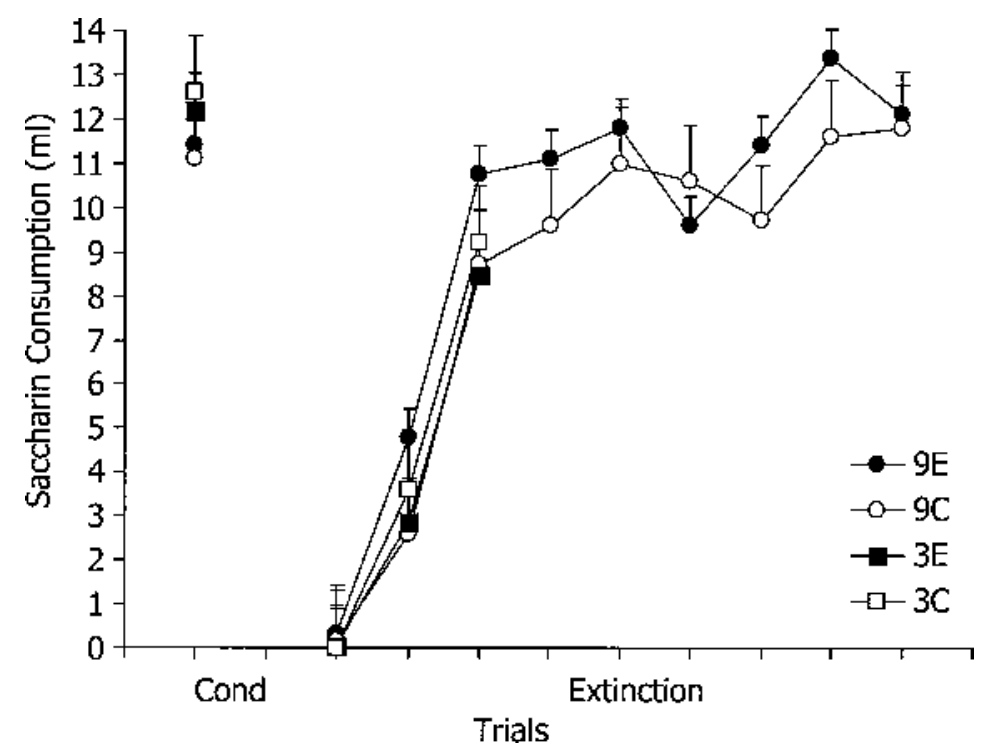

Figure 1. Group mean consumption of saccharin on the conditioning trial (Cond) and the three or nine extinction trials (right) for Groups 9E, 9C, 3E, and 3C in Experiment 1.

drank more than did Group 9C $[F(1,26)=7.36]$ but that Groups $3 \mathrm{E}$ and $3 \mathrm{C}$ did not differ $(F<1)$.

The findings with Group 9E are consistent with those reported by Calton et al. (1996) in showing that a flavor aversion extinguished for nine trials passes a summation test (see also Schachtman et al., 2000). The new finding is that a flavor extinguished for three trials did not pass the test. Interestingly, in the extinction phase, terminal saccharin consumption was similar in the three- and the ninetrial conditions. Extinction appeared to be complete with three trials (cf. Rosas \& Bouton, 1996, who did not di- rectly compare the effects of different amounts of extinction). The results are in line with the suggestion that extended extinction (i.e., beyond behavioral extinction) may be important for producing a flavor stimulus with conditioned inhibitory properties (Bouton, 1986; Calton et al., 1996; Hart et al., 1995). However, no control conditions were included to assess stimulus generalization decrement on the test. The novel combination of saccharin and vinegar may have distracted the E-group rats and/or disrupted their drinking (Aguado et al., 2001). This is of particular concern for Group 9E because it passed the test.

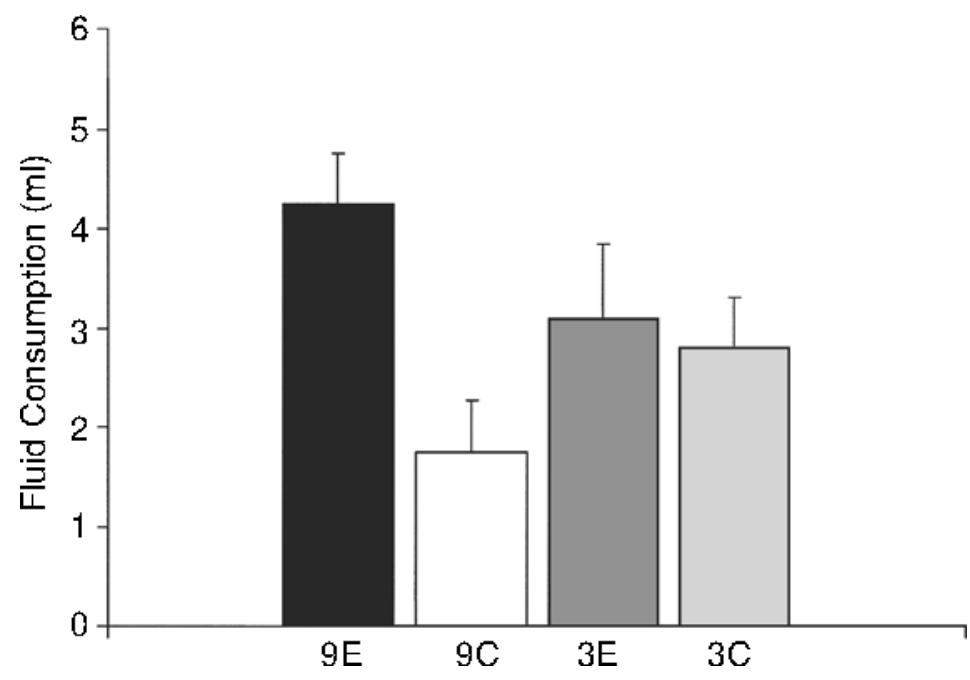

Figure 2. Group mean consumption of vinegar (Groups $9 \mathrm{C}$ and $3 \mathrm{C}$ ) or saccharin + vinegar (Groups $9 \mathrm{E}$ and $3 \mathrm{E}$ ) on the two-trial block of the summation test in Experiment 1. 


\section{EXPERIMENT 2}

This experiment was designed to replicate Experiment 1's summation test result after nine extinction trials and to assess the role of generalization decrement in that result. The design is shown in Table 1. There were four groups. Groups $9 \mathrm{E}$ and $9 \mathrm{C}$ were treated exactly as the groups of the same name in Experiment 1. Groups YE and $\mathrm{YC}$ tested for generalization decrement due to the novel combination of vinegar and saccharin on the summation test. They were treated similarly to Groups $9 \mathrm{E}$ and $9 \mathrm{C}$, respectively, with two exceptions. In the conditioning phase, the CS and the unconditioned stimulus (US) were unpaired. In the conditioning and extinction phases, a yoking technique was used to equate Group YE's flavor consumption with Group 9E's and to equate Group YC's with Group 9C's. No previous taste aversion experiments have used controls with equated exposure to the test stimulus. If generalization decrement explains the summation result demonstrated by Groups $9 \mathrm{E}$ and 9C in Experiment 1, then during testing, Group YE should consume more than Group YC. However, if that result was due to conditioned inhibition in Group 9E, Groups YE and YC should not differ.

\section{Method}

Subjects and Apparatus. The subjects were 32 naive female Wistar rats bred at Denison University. They were approximately 150 days old and ranged in weight from 300 to $375 \mathrm{~g}$ at the start of the experiment. They were individually housed in suspended wire cages in a room maintained on a 14:10-h light:dark cycle; the light part of the cycle began at $0630 \mathrm{~h}$. Food was available in the home cages throughout the experiment.

A room $40 \mathrm{~m}$ from the colony room was used for all flavored solution presentations. It contained a table with drinking boxes on it. The table was similar to that used in the other experiments reported here; the boxes were the same boxes as those used in the other experiments. Illumination was provided by one $40-\mathrm{W}$ incandescent bulb centered above the boxes and positioned approximately $1.6 \mathrm{~m}$ above the lids of the boxes. A 55-dB fan provided masking noise. The CSs and the US were the same as those in Experiment 1.

Procedure. The experiment was conducted on consecutive days. All the drinking sessions were $15 \mathrm{~min}$, and distilled water was used. The schedule of two drinking sessions per day was the same as that in Experiment 1. Only the first drinking session will described. On the first 5 days, all the rats received water. On the first 2 of those days, water was given in the colony room. On the next day, all the rats received $15 \mathrm{~min}$ of exposure to the drinking boxes, during which they received no fluid, followed within $90 \mathrm{~min}$ by a waterdrinking session in the colony room. On the next 2 days, water was given in the drinking boxes. The rats were then assigned to Groups $9 \mathrm{E}, 9 \mathrm{C}, \mathrm{YE}$, and $\mathrm{YC}(n \mathrm{~s}=8)$, balanced on water intake during these 5 days.

The next 2 days constituted the conditioning phase. On each day, all the rats had drinking sessions in the drinking boxes. On the 1st of these days, Groups YE and YC received free access to saccharin, and Groups 9E and 9C received water. On the 2nd day, Groups 9E and 9C received saccharin, and Groups $\mathrm{YE}$ and $\mathrm{YC}$ received water; these drinking sessions were followed within 10 min by an injection of $\mathrm{LiCl}$. Injections were given in the corridor outside the room that contained the drinking boxes. Immediately following the injection, each rat was placed back in its drinking box for approximately $5 \mathrm{~min}$ (with no fluids available) and was then returned to its cage in the colony room. The conditioning phase procedures provided for the unpairing of the CS and the US in Groups YE and YC and controlled both saccharin consumption and the initial US-totesting interval among all groups. On the day after conditioning, each rat received a recovery day on which a water-drinking session was given in the colony room.

On each of the next 9 days, all the groups received access to saccharin for $15 \mathrm{~min}$ in the drinking boxes without $\mathrm{LiCl}$. Consumption in Groups YE and YC was yoked to that in Groups 9E and 9C, respectively. Yoking was accomplished by providing to Groups YE and $\mathrm{YC}$ the average of the saccharin volume consumed by Groups $9 \mathrm{E}$ and $9 \mathrm{C}$, respectively. One rat from Group 9E did not show evidence of extinction (the same criterion was used as that in Experiment 1); its data were eliminated from the study (Group 9E, $n=7$ ).

On the day following the end of extinction, all the groups received conditioning with vinegar and $\mathrm{LiCl}$, using the same procedure as that in Experiment 1; all the groups had free access to vinegar on this day. (We chose not to yoke vinegar consumption in order to demonstrate that the groups' natural tendency to consume a new flavor did not differ prior to testing, a determination that was not possible in the earlier phases, and one that is important for interpreting the test results.) The next day was a recovery day. The next 2 days made up the summation test. The testing procedure was the same as that in Experiment 1: Groups 9E and $\mathrm{YE}$ received free access to the vinegar-saccharin compound; Groups 9C and $\mathrm{YC}$ received free access only to vinegar.

\section{Results and Discussion}

Because consumption was yoked in the conditioning and the extinction phases, there was little reason to expect group differences in those phases. There were none $(F \mathrm{~s}<1)$. Mean saccharin consumption in the conditioning phase averaged $11.8,11.6,12.2$, and $12.0 \mathrm{ml}$ for Groups 9E, 9C, YE, and YC, respectively. All the groups consumed less saccharin on the first extinction trial, as compared with consumption in the conditioning phase $[F(1,27)=356.57]$. Mean saccharin consumption on the first and the last extinction trials averaged 0.2 and $12.7 \mathrm{ml}$ for Group 9E and 0.1 and $12.5 \mathrm{ml}$ for Group 9C; consumption for Groups YE and YC was similarly patterned on those trials. Terminal extinction consumption in Groups 9E and 9C was statistically similar to that in conditioning $\left(F_{\mathrm{S}}<1\right)$; note that this finding is not typical (cf. Bevins, Jensen, Hinze, \& Besheer, 1999; Rosas \& Bouton, 1996). Mean vinegar consumption on the vinegar conditioning trial averaged 5.7, 6.0,5.2, and $6.2 \mathrm{ml}$ for Groups 9E, 9C, YE, and YC, respectively $(F<1)$.

Figure 3 shows the results of the summation test. Group 9E drank more fluid than did Group 9C. And Group YE drank more fluid than did Group YC. A conditioning treatment (CS and US paired vs. unpaired) $X$ text condition (compound vs. vinegar alone) ANOVA on the two-trial block of the test revealed an effect of test condition $[F(1,27)=16.54]$, indicating greater overall consumption of the compound. There was no effect of conditioning treatment and no interaction $(F \mathrm{~s}<1)$. Comparisons revealed differences both between Groups $9 \mathrm{E}$ and 9C and between Groups YE and YC [smallest $F(1,27)=$ 7.71]. Consumption did not differ between Groups 9E and $\mathrm{YE}$, and it did not differ between Groups 9C and YC $\left(F_{\mathrm{S}}<1\right)$. 


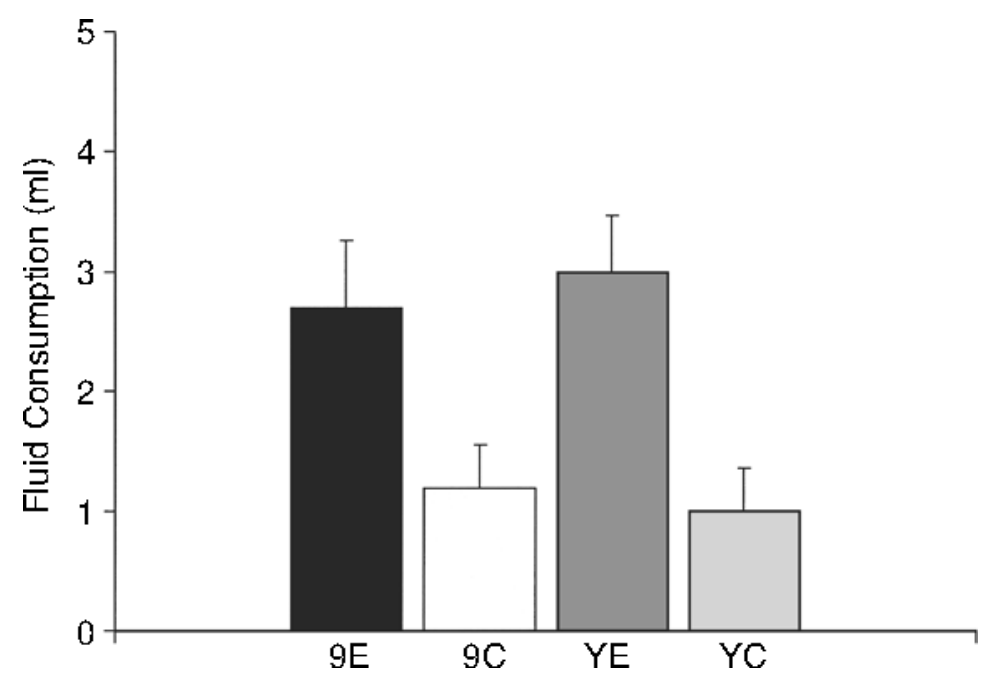

Figure 3. Group mean consumption of vinegar (Groups $9 \mathrm{C}$ and $\mathrm{YC}$ ) or saccharin + vinegar (Groups 9E and YE) on the two-trial block of the summation test in Experiment 2.

Groups 9E and 9C replicated the summation test result from Experiment 1. However, the difference between Groups YE and YC calls into question the conditioned inhibition view of the results with Groups 9E in this experiment and in Experiment 1. Together with the results of recent summation tests reported by Aguado et al. (2001), that difference conflicts with the view suggested by Calton et al. (1996) that extended extinction using CTA yields conditioned inhibition. A more parsimonious interpretation involves generalization decrement. Thus, after nine extinction trials, the saccharin flavor appears to have distracted the rats from vinegar or to have enhanced compound consumption by another nonassociative mechanism. The test results of Experiment 1 indicate that the mechanism producing the enhanced compound consumption requires more than three extinction trials, suggesting that familiarity, or extent of exposure, may be critical to the nonassociative effect.

Experiment 2 confirms and extends the summation test results from Aguado et al. (2001). The aversion to the excitor element did not differ between Groups YC and $9 \mathrm{C}$ during testing. The similarity among the four groups on the vinegar conditioning trial makes it difficult to interpret the summation test results in the present experiment as being due to preexisting differences in the tendency to consume fluids. Aguado et al. (2001) did not find similar element responding in their Experiment 3, thus confounding interpretation of those results. They did, however, find similar element responding in their Experiment 4, which yielded results consistent with the generalization decrement interpretation. Each of their tests compared consumption of element and compound flavors within subjects without balancing the order in which those flavors were consumed. That procedure leaves open the possibility of sequence effects, which the present between-subjects design avoids. In addition, yoking equated the exposure to saccharin among the groups throughout the experiment. This had two central advantages. It avoided the potential, if saccharin had been accessed freely prior to testing, that compound consumption in Group YE would be enhanced owing to greater saccharin familiarity. It also avoided the potential, if saccharin had been presented for the first time during testing, that neophobia would occur. Another advantage of this experiment is that the unpaired control procedure may be viewed as a more stringent test for conditioned inhibition than has previously been employed in CTA experiments in which the effects of extinction have been investigated.

Overall, the present finding is consistent with the report by Aguado et al. (2001) in suggesting that positive summation results after extinction in CTA are due to generalization decrement; thus, the present finding appears to be at odds with Calton et al.'s (1996) report of conditioned inhibition after nine extinction trials. Experiment 2 produced evidence of generalization decrement, but Calton et al.'s Experiments 2 and 3B did not. Although our experiments were designed to be procedurally similar to Calton et al.'s experiments, several differences between them could account for the different generalization decrement control results. The experiments were conducted in different laboratories by different researchers using different rat strains (we used Wistars, whereas Calton et al. used Sprague-Dawleys); however, it is difficult to know how those differences could account for the different results. Differences in flavors and flavor concentrations may account for the different findings. We used $0.05 \%$ saccharin and $2 \%$ vinegar solutions, whereas Calton et al. used $0.1 \%$ saccharin and $3 \%$ vinegar solutions. Calton et al. used a coffee solution during the conditioning phase in their control groups, whereas coffee was not used in these experiments. 
Parameters such as these may be critical to producing or preventing stimulus generalization decrement. Still, it is not clear by what precise mechanism these parameter differences could have produced the different results.

More likely factors are design and test duration differences. Our Experiment 2 used an $\mathrm{LiCl} / \mathrm{saccharin}$ unpairing procedure during the conditioning phase; Calton et al. (1996) did not use such a procedure but, rather, gave control subjects a flavor other than saccharin. The controls in our experiment received the target flavor (saccharin) during conditioning and extinction. Furthermore, consumption of the flavor was carefully equated between control and experimental groups throughout the experiment prior to testing. These conditions were not present in Calton et al.'s Experiments 2 and 3B. One especially likely reason for the generalization decrement result obtained here is that summation testing involved two trials, whereas in Calton et al.'s experiments it involved only one trial. Overall, in both of their summation test experiments, test consumption was very low and may have represented a floor effect that masked generalization decrement. Although generalization decrement would be expected to operate on the first test trial in tests involving strong excitor elements (e.g., ours and Calton et al.'s), it may not be readily demonstrated until after that trial. Also note that in Calton et al.'s experiments, the pattern of test consumption of the compound by rats given conditioning and extinction with saccharin is a cause for concern. Compound consumption averaged approximately $11 \mathrm{ml}$ in their Experiment 2, whereas it averaged approximately $1.7 \mathrm{ml}$ in their Experiment 3B. The reason for the different consumption between experiments is unclear; consequently, the summation result in Experiment $3 \mathrm{~B}$ is not as convincing as it could be.

The present finding can be interpreted as among the clearest evidence that extensive extinction produces latent inhibition rather than conditioned inhibition. Latent inhibition may simply be stronger after nine extinction trials than after three (cf. Calton et al., 1996; Danguir \& Nicolaidis, 1977; Hart et al., 1995). However, in the absence of other evidence, the results from this experiment do not rule out the possibility that the control conditions produced conditioned inhibition, in which case the experimental condition (Group 9E in Experiments 1 and 2) could be interpreted as having produced conditioned inhibition. If so, the single unpairing of saccharin and $\mathrm{LiCl}$ in the Y groups plus nine CS-alone exposures could not be considered an appropriate control for generalization decrement. Yet those unpaired and yoked controls are arguably among the best ones yet employed for this type of experiment. The likelihood that extended extinction may yield latent inhibition, rather than conditioned inhibition, is reconsidered in the General Discussion section, once all of the experiments have been reported.

\section{EXPERIMENT 3}

Experiment 3 involved a retardation test after the same saccharin conditioning and extinction procedures as those used in Experiment 1. The objective was to assess the rate of saccharin aversion reacquisition after three or nine extinction trials. On the test, that rate was compared with the rate of saccharin aversion conditioning in other groups given previous conditioning and extinction with a control flavor (saline; see, e.g., Calton et al., 1996; Hart et al., 1995). Table 1 shows the design. There were four groups that initially received conditioning and extinction with either saccharin (Groups 9E and 3E) or saline (Groups 9C and 3C). Then, in the crucial portion of the test phase, all the groups received each of two saccharin drinks paired with $0.1 \mathrm{M}$ of $\mathrm{LiCl}$. A weaker $\mathrm{LiCl}$ solution than that in the previous experiments was used to make the test sensitive to retardation - that is, to minimize the chance of obtaining asymptotic conditioning in all groups after the first retardation test trial. The most convincing evidence of (latent or conditioned) inhibition comes from this reconditioning phase of the test, where inhibition would be demonstrated by slower reconditioning of the aversion in the groups that received initial saccharin conditioning and extinction (Groups 9E and $3 \mathrm{E}$ ), as compared with those given saccharin-LiCl pairings for the first time (Groups $9 \mathrm{C}$ and $3 \mathrm{C}$ ). On the basis of the results from Experiment 1, we expected Group 9E, but not Group 3E, to show slow reconditioning in this phase. In the second phase of the test, all the groups received reextinction trials with saccharin.

\section{Method}

Subjects and Apparatus. The subjects were 32 naive Wistar rats bred at CSUF (20 female and 12 male). They were approximately 130 days old and ranged in weight from 210 to $300 \mathrm{~g}$ (females) and from 350 to $450 \mathrm{~g}$ (males) at the start of the experiment. The groups were balanced by sex. Maintenance conditions and apparatus were the same as those in Experiment 1. A 1.3\% saline solution was used as the control fluid.

Procedure. The experiment was run on consecutive days. All the drinking sessions were $15 \mathrm{~min}$, and distilled water was used. The schedule of two drinking sessions per day was carried out as in the prior experiments. Only the first drinking session will be described. On the first 7 days, all the rats received water. On the first 2 of those days, water was given in the colony room. On the next day, all the rats received $15 \mathrm{~min}$ of exposure to the drinking boxes, during which they received no fluid, followed within $90 \mathrm{~min}$ by a waterdrinking session in the colony room. On the next 4 days, water was given in the drinking boxes. The rats were then assigned to Groups $9 \mathrm{E}, 9 \mathrm{C}, 3 \mathrm{E}$, and $3 \mathrm{C}(n \mathrm{~s}=8)$, balanced on water intake during these 7 days.

The conditioning and extinction procedures were the same as those received by the groups of the same name in Experiment 1, except that Groups 9C and 3C received saline instead of saccharin. The phases were arranged so that all the groups were tested on the same days and were on the drinking schedule the same number of days, in order to equate the motivation to drink in all the groups during testing. As in the prior experiments, all four groups were tested on the same days and received the schedule of two drinks per day for the same total number of days prior to testing. Using the same criteria as in the prior experiments, we identif ied 2 rats from Group 9E that did not drink sufficient saccharin during conditioning and 1 rat from each of Groups 9E, 9C, and 3E and 2 rats from Group $3 \mathrm{C}$ that failed to show evidence of extinction. The data from those rats were eliminated from the study (the resulting $n \mathrm{~s}=5,7,7$, and 6, for Groups 9E, 9C, 3E, and 3C, respectively). 
Testing began on the day following the end of extinction. All the groups received the same procedure. On the 1 st and 3rd test days, a saccharin-drinking session was followed within 10 min by a $0.1-\mathrm{M}$ $\mathrm{LiCl}$ injection. The $2 \mathrm{nd}$ and 4 th test days were recovery days. For each of the 8 days afterward (Test Days 5-12), all the rats received $15 \mathrm{~min}$ of access to saccharin without $\mathrm{LiCl}$.

\section{Results and Discussion}

There were no differences among the groups during conditioning or extinction. Consumption on the conditioning trial averaged 9.2, 10.7, 9.6, and $11.2 \mathrm{ml}$ for Groups 9E, 9C, 3E, and 3C, respectively. An extinction trials (9 vs. 3 ) $\times$ flavor (used prior to testing; saccharin vs. saline) ANOVA revealed no effects and no interaction $[F \mathrm{~s}(1,21)<2.17, p \mathrm{~s}>.15]$. Consumption on the first extinction trial averaged 1.0,1.0, 0.9, and $0.8 \mathrm{ml}$ for Groups 9E, 9C, 3E, and 3C, respectively. A trial (conditioning vs. first extinction) $\times$ extinction trials $\times$ flavor ANOVA revealed an effect of trial $[F(1,21)=239.11]$, but no other effects and no interactions $\left[F_{\mathrm{s}}(1,21)<2.08\right.$, $p s>.16]$. There were also no differences among the groups during Extinction Trials 1-3; a trial $\times$ extinction trials $\times$ flavor ANOVA revealed an effect of trial $[F(1,21)=$ $79.99]$ but no other effects and no interactions $\left(F_{\mathrm{s}}<\right.$ $1.73, p s>.20$ ). The groups also did not differ on their respective final extinction trial (Trial 3 for Groups 3E and 3C, Trial 9 for Groups 9E and 9C; consumption on that trial averaged 9.1, 10.3, 8.9, and $8.7 \mathrm{ml}$ for Groups 9E, 9C, $3 \mathrm{E}$, and $3 \mathrm{C}$, respectively). An extinction trials $\times$ flavor ANOVA on that trial revealed no effects or interaction $[F \mathrm{~s}(1,21)<3.14, p \mathrm{~s}>.09]$.

The left portion of Figure 4 shows the two reconditioning trials during which all the groups received saccharin, followed by $0.1 \mathrm{M} \mathrm{LiCl}$. On the first trial, the groups did not differ; however, on the second trial,
Group 9E had a weaker aversion than did the other groups. An extinction trials $\times$ flavor ANOVA on the first test trial revealed no effects or interactions $[F \mathrm{~s}(1,21)<$ $3.49, p \mathrm{~s}>.07]$. A similar ANOVA on the second test trial revealed an effect of extinction trials $[F(1,21)=21.63]$ and of flavor $[F(1,21)=23.58]$ and an interaction $[F(1,21)=23.58]$. Most important, comparisons on that second trial revealed that Group 9E consumed more saccharin than did each of the other groups [smallest $F(1,21)=39.56]$. Groups 9C, 3E, and 3C did not differ [largest $F(1,21)<1]$.

The right portion of Figure 4 shows the reextinction trials. Group 9E continued to differ from the other groups. A trials $\times$ extinction trials $(9$ vs. 3$) \times$ flavor ANOVA on the eight reextinction test trials revealed an effect of extinction trials $[F(1,21)=17.63]$, an effect of flavor $[F(1,21)=8.81]$, and an extinction trials $\times$ flavor interaction $[F(1,21)=$ 11.22]. There was also an effect of trial $[F(7,147)=33.80]$ and a trial $\times$ extinction trials interaction $[F(7,147)=$ $2.28]$ but no other interactions $[F \mathrm{~s}(7,147)<1]$. However, comparisons on each test trial revealed that Group 9E differed from the other groups on Reextinction Trials $1-5\left[F_{\mathrm{s}}(1,21)>5.93\right]$ and that the other groups never differed from each other (largest $F<1$ ).

Although many experiments have assessed taste aversions reconditioned after extinction in CTA, this is the first direct comparison of the effect of different numbers of extinction trials. Group 9E demonstrated a weaker saccharin aversion during reconditioning than did Group 9C. That difference was maintained during reextinction. Throughout testing, Group 3E never differed from Group 3C. Thus, in the same experiment, a flavor extinguished nine times passed a retardation test (Calton et al., 1996), but one extinguished three times did not

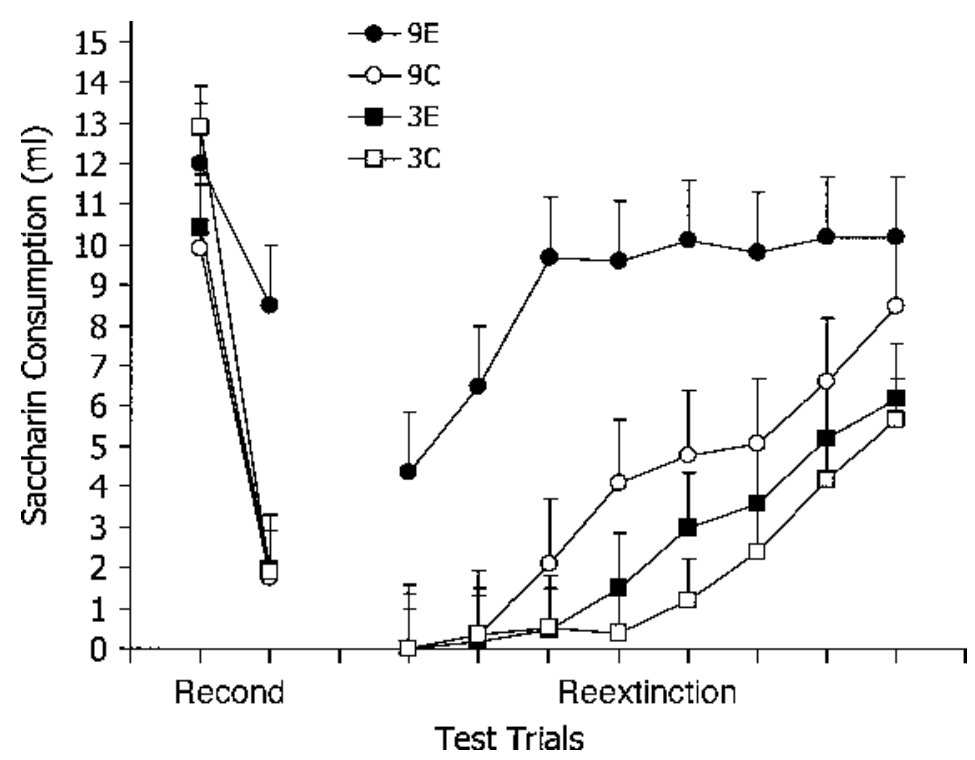

Figure 4. Group mean saccharin consumption on the two reconditioning trials (Recond, left) and the eight reextinction trials (right) of testing in Experiment 3 . 
(e.g., Hart et al., 1995, Experiment 1). The crucial retardation effect in Group 9E was found during the reconditioning phase, rather than only as a more rapid reextinction (cf. Aguado et al., 2001; Calton et al., 1996). The finding that the groups did not differ on the first test trial argues against neophobia in the control groups that received saccharin for the first time during testing. Furthermore, there is no methodological reason to expect neophobia to differ in Groups 9C and 3C during testing. The test results are consistent with the conclusion that extended extinction with nine trials produces a form of inhibition (latent or conditioned inhibition; Rescorla, 1969). In contrast, just three extinction trials yielded no apparent inhibition. Once again, extinction appeared to be complete with three trials; consumption at the end of extinction did not differ between the groups given three or nine extinction trials (cf. Experiment 1; Hart et al., 1995; Rosas \& Bouton, 1996).

\section{EXPERIMENT 4}

In Experiment 4, we further evaluated the effect of nine or three extinction trials, using a two-bottle preference test. Best (1975; Best et al., 1985) used such a test to assess conditioned inhibition after $\mathrm{A}+/ \mathrm{AX}$ - training (see also Delamater et al., 1986). To our knowledge, inhibition after simple extinction has not been assessed with a preference test. Such a test is less widely accepted than Rescorla's (1969) summation and retardation tests. However, a rationale has been given for its use as a test of conditioned inhibition (see Savastano et al., 1999, pp. 107-109, for a review). Hearst and Franklin (1977; Wasserman, Franklin, \& Hearst, 1974) suggested that approach-withdrawal assays are worthy alternatives to Rescorla's dual-test strategy. In appetitive conditioning, Hearst and Franklin found that after differential inhibition training $(\mathrm{A}+/ \mathrm{X}-)$, pigeons approached and pecked a response key when $\mathrm{A}$ was present and also withdrew from the key when $\mathrm{X}$ was present. The withdrawal response in appetitive conditioning was viewed as indicating conditioned inhibition. A reasonable analogue in the CTA method is that approach toward and relatively greater consumption of a flavor, relative to a control condition, should provide a direct measure of conditioned inhibition.

The equivocal findings with preference tests using CTA (e.g., Best, 1975; Best et al., 1985; Delamater et al., 1986; LoLordo \& Fairless, 1985), along with Hearst and Franklin's (1977) assertion, suggest the need to further investigate the utility of such tests in investigations of inhibition. We were interested in the convergent validity of preference tests with respect to the more widely accepted summation and retardation tests. In Experiments 4 and 5, we included preference tests following conditioning and extinction procedures like those used in Experiments $1-3$. The design of Experiment 4 is shown in Table 2. Groups 9 and 3 each received conditioning and extinction with saccharin, followed by a two-bottle preference test involving concurrent access to saccharin and water.
The findings from Experiments 1-3 and those from Best (1975; Best et al., 1985) suggest that Group 9 should have a greater preference for saccharin than does Group 3. Group Exposure (EX) was included to assess unconditioned preference for (approach to) saccharin during testing. It resembled a latent inhibition control; it received the same number of saccharin exposures as Group 9, but saccharin was not paired with LiCl. Approach accounts (Hearst \& Franklin, 1977; Wasserman et al., 1974) predict that if conditioned inhibition develops with extended extinction, Group 9 should demonstrate greater consumption of saccharin than of water on the test and a greater saccharin preference than that in Group EX (see Bevins et al., 1999). That result would be consistent with conditioned inhibition. Experiment 2, however, suggests that extended extinction may yield latent inhibition, rather than conditioned inhibition. If so and if a preference test converges on the same mechanism as the summation and retardation tests, there is no reason to expect Group 9 to have a greater saccharin preference than Group EX.

\section{Method}

Subjects and Apparatus. The subjects were $42 \mathrm{Wistar}$ rats bred at CSUF (27 female and 15 male). They were approximately 140 days old and ranged in weight from 235 to $275 \mathrm{~g}$ (females) and from 350 to $425 \mathrm{~g}$ (males) at the start of the experiment. Prior to this experiment, the rats had participated in an appetitive conditioning experiment in which they received a white keylight, an intermittent noise, and food pellets. The rats were assigned to groups in this experiment orthogonally to groups in the earlier experiment and closely balancing by sex. Maintenance conditions and apparatus were the same as those in the previous experiments, except that the lids of the drinking boxes had two additional drinking tube holes located $3 \mathrm{~cm}$ to the left and right of the center hole.

Procedure. The experiment was run on consecutive days and was conducted in two replications. All drinking sessions were 15 min in duration, and distilled water was used. The schedule of two drinking sessions per day was similar to that in the previous experiments. Only the first drinking session will be described. On the first 9 days, all the rats received water. On the first 2 of those days, water was given in the colony room. On the next day, all the rats received $15 \mathrm{~min}$ of exposure to the drinking boxes, during which they received no fluid, followed within $90 \mathrm{~min}$ by a water-drinking session in the colony room.

Table 2

Design of Experiments 4 and 5

\begin{tabular}{|c|c|c|c|c|}
\hline Group & Pretraining & Conditioning & Extinction & Test \\
\hline \multicolumn{5}{|c|}{ Experiment 4} \\
\hline 9 & & Sac+ & $9 \mathrm{Sac}-$ & $\mathrm{Sac}-$ vs. water \\
\hline 3 & & $\mathrm{Sac}+$ & $3 \mathrm{Sac}-$ & $\mathrm{Sac}-$ vs. water \\
\hline EX & & $+/ \mathrm{Sac}-$ & $9 \mathrm{Sac}-$ & $\mathrm{Sac}-$ vs. water \\
\hline \multicolumn{5}{|c|}{ Experiment 5} \\
\hline $9 \mathrm{~N}$ & $3 \mathrm{Sal}-$ & $\mathrm{Sac}+$ & $9 \mathrm{Sac}-$ & $\mathrm{Sac}-$ vs. Sal- \\
\hline $3 \mathrm{~N}$ & $3 \mathrm{Sal}-$ & $\mathrm{Sac}+$ & $3 \mathrm{Sac}-$ & $\mathrm{Sac}-$ vs. Sal- \\
\hline EXN & $3 \mathrm{Sal}-$ & $+/ \mathrm{Sac}-$ & $9 \mathrm{Sac}-$ & $\mathrm{Sac}-$ vs. Sal- \\
\hline CI & $8 \mathrm{~A}+/ 8 \mathrm{ASal}-$ & $+/ \mathrm{Sac}-$ & $9 \mathrm{Sac}-$ & $\mathrm{Sac}-$ vs. Sal- \\
\hline
\end{tabular}

Note- "Sac" indicates the $0.05 \%$ saccharin solution; "Sal" indicates a $1.3 \%$ saline solution; "A" indicates the drinking box apparatus; "+" indicates lithium chloride; "-" indicates no US; numbers in the pretraining and extinction phases refer to number of trials. 
For the remainder of the experiment, all the rats received the first drinking session of each day in the drinking boxes. On the next 6 days, water was given in the boxes. A procedure was used to accustom the rats to receiving fluid from the center drinking tube position as well as concurrently from two different tubes at the left and right drinking tube positions, since the preference test involved the latter arrangement. On each of the first 2 of those 6 days, each rat drank from a single tube positioned in either the left or the right hole of the drinking box lid (the left/right sequence was counterbalanced over these 2 days). On the 3rd of those 6 days, each rat drank from a single tube positioned in the center hole of the lid. On the final 3 of the 6 days, each rat received one tube positioned in the left and one concurrently in the right hole of the lid. The rats were then assigned to Groups 9,3 , and $\operatorname{EX}(n \mathrm{~s}=15,15$, and 12 , respectively), matched on water intake during these 6 days and balanced on their left/right consumption.

On the next day, all the groups received another water-drinking session. Within 10 min following this drink, Group EX received an injection of $0.3 \mathrm{M} \mathrm{LiCl}$. The other groups remained in the boxes for 10 min following the drink but did not receive an injection. On the next day, Group 9 received saccharin followed by $\mathrm{LiCl}$. The next day was a recovery day, which was then followed by nine daily saccharin extinction drinks. Group EX was treated the same as Group 9, except that no $\mathrm{LiCl}$ was given after saccharin. Conditioning for Group 3 began 7 days after conditioning for the other groups; Group 3 then received a recovery day and three extinction trials. Conditioning and extinction were delayed for Group 3 so that each group's extinction phase would end on the same day; thus, testing took place on the same days for all the groups. This procedure again equated the motivation to drink in all the groups at the time of testing. Each group received the schedule of two drinks per day for the same total number of days prior to testing. For all the conditioning and extinction drinking sessions, each group received the drinking tube placed in the center hole of the box lid. Using the same criteria as before, we identified 2 rats from Group 9 that did not drink sufficient saccharin during conditioning and 1 rat from Group 9 and 2 from Group 3 that failed to show evidence of extinction. The data from those rats were eliminated from the study (the resulting $n \mathrm{~s}=12,13$, and 12 , for Groups 9, 3, and EX, respectively).

Four days of testing began on the day following the end of extinction. All the groups received the same test procedure, which closely followed that used by Best (1975; Best et al., 1985). On each day, a drinking tube was placed into each of the right and left holes in the lid of each drinking box. One contained saccharin, and the other contained water. The left-right position of saccharin and water was counterbalanced within each group and over test days; it was also balanced over the replications. On each test trial, each rat's water and saccharin consumption was converted to a preference score representing saccharin consumption divided by the sum of saccharin and water consumption (see, e.g., Best et al., 1985).

\section{Results and Discussion}

There were no effects due to replication or to any of the counterbalancing factors; therefore, analyses including those factors are not included. The three groups did not differ on their initial consumption of saccharin, which constituted the conditioning trial for Groups 9 and 3 (Group EX received only saccharin then). Consumption averaged 10.4, 11.3, and $10.8 \mathrm{ml}$, for Groups 9, 3, and EX, respectively. An ANOVA revealed no difference among the groups $[F(2,34)<1]$. On the first trial of the extinction phase, saccharin consumption averaged 0.2 , 0.3 , and $13.0 \mathrm{ml}$ for Groups 9, 3, and EX, respectively. A trial $\times$ group ANOVA comparing initial saccharin consumption with that on the first extinction phase trial re- vealed an overall effect of trial $[F(1,34)=150.40]$ and of group $[F(2,34)=60.64]$ and an interaction $[F(2,34)=$ 70.19]. Comparisons on the first trial of the extinction phase revealed that Groups 9 and 3 each consumed less than did Group EX [smallest $F(1,34)=69.50$ ] and that Groups 9 and 3 did not differ [largest $F(1,45)<1]$. On the third trial of the extinction phase, consumption averaged 5.3, 5.8, and $13.5 \mathrm{ml}$ for Groups 9, 3, and EX, respectively. A trial $\times$ group ANOVA on the first three extinction trials revealed an overall effect of trial $[F(2,68)=52.00]$ and of group $[F(2,34)=115.68]$ and an interaction $[F(4,68)=9.19]$. Groups 9 and 3 did not differ on those trials $\left(F_{\mathrm{S}}<1\right)$ and continued to consume less than Group EX on each of those trials [smallest $F(1,34)=37.17]$. An ANOVA comparing the groups on their respective final trial of the extinction phase (Trial 3 for Group 3, Trial 9 for Groups 9 and EX) showed that the groups differed $[F(2,34)=28.02]$. (Consumption averaged 10.6 and $13.2 \mathrm{ml}$ for Groups 9 and EX on that trial; that difference is consistent with findings by Bevins et al., 1999.) Comparisons revealed that Group EX consumed more saccharin than did the other groups $[F \mathrm{~s}(1,34)>6.17]$. And Group 3 consumed less than Group $9[F(1,34)=5.12]$, indicating that three extinction trials did not reduce the saccharin aversion to the degree that nine trials did. This contrasts with the final extinction trial results of Experiments 1 and 2. Prior to testing, Group EX clearly consumed more saccharin than did the other groups.

Figure 5 shows the 2 two-trial blocks of the two-bottle preference test. The results were the same on each block of the test. An ANOVA comparing the groups on all four trials combined revealed overall differences among the groups $[F(2,34)=23.46]$. Comparisons revealed that the preference for saccharin was greater for Group 9 than for Group $3[F(1,34)=7.05]$. The saccharin preference was greater for Group EX than for the other groups [smallest $F(1,34)=13.48]$. And as is clear from the figure, only Group EX showed a greater preference for saccharin over water. Its mean preference score was significantly greater than a hypothetical population mean of .5 [which indicates no absolute preference; $t(11)=10.20]$. Groups 9 and 3 clearly did not prefer saccharin over water. Group 9 did not differ from a hypothetical population mean of $.5[t(11)<1]$, indicating no preference for saccharin over water. Group 3 differed from a hypothetical population mean of $.5[t(12)=9.82]$, indicating a weaker preference for saccharin than for water. Overall consumption during testing (saccharin plus water) did not differ among the groups $[F(2,34)<2.10, p>.13]$.

Extinction with nine trials produced a relatively greater saccharin preference than three trials did, a result consistent with the pattern of results from the previous experiments in suggesting that a form of behaviorally demonstrable inhibition appears after more than three trials. There was no evidence of conditioned inhibition. Group 9 did not demonstrate a greater saccharin preference than did the latent inhibition control group (Group EX), nor did Group 9 prefer saccharin over water. Different num- 


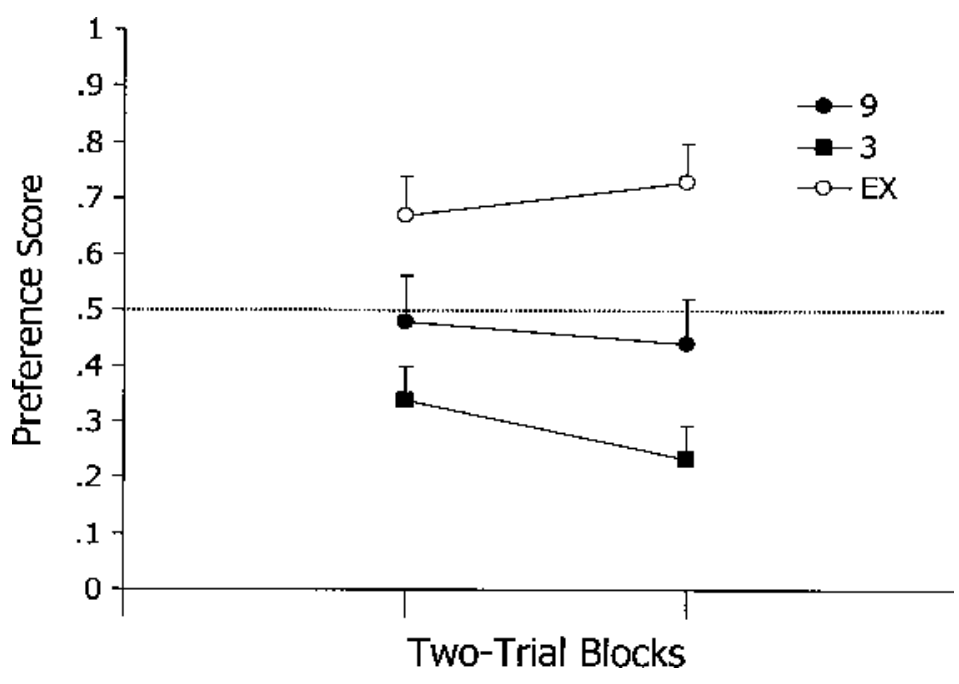

Figure 5. Group mean preference scores (saccharin/saccharin + water) on the 2 two-trial blocks of the preference test in Experiment 4.

bers of extinction trials likely produce different degrees of latent inhibition (see Ayers, Philbin, Cassidy, Bellino, \& Redlinger, 1992; Lubow, 1989). Three or fewer trials may produce no inhibition or, perhaps, inhibition that was not detectable with the present tests. Group EX might have acquired stronger latent inhibition than did Group 9. With the present method and procedures, a preference test may have convergent validity with summation and retardation tests for the demonstration of latent inhibition, rather than conditioned inhibition.

The procedures and results of Experiment 4 do not completely rule out the possibility that a preference test could yield evidence of conditioned inhibition. Although we followed Best's (1975; Best et al., 1985) testing procedures closely, the test might have failed to produce evidence of inhibition because of limitations inherent in those procedures. One reason for not finding a greater saccharin preference in Group 9 than in Group EX is that the test's sensitivity may have been reduced by the use of water as the comparison fluid. That could have led to overall lower saccharin preference, since water is typically safe and highly familiar. Group EX's greater saccharin preference may have been inflated because it was the only group that received water paired with $\mathrm{LiCl}$ (during the conditioning phase). In principle, a mild aversion to water might have heightened Group EX's acceptance of saccharin, thus reducing the likelihood that Group 9 would show a greater saccharin preference than would Group EX. Thus, a comparison fluid other than water may be more appropriate. Another possible reason for Group EX's greater preference during testing is that it simply drank more saccharin than did the other groups during extinction.

\section{EXPERIMENT 5}

Experiment 5 addressed the possible limitations of Experiment 4. The design is shown in Table 2. During conditioning and extinction in this experiment, Groups $9 \mathrm{~N}$ and $3 \mathrm{~N}$ were treated just as Groups 9 and 3 (respectively) were in Experiment 4. Here, all the groups received saline rather than water as the comparison fluid during testing; otherwise, the test procedures were the same as those in Experiment 4. Water was not paired with $\mathrm{LiCl}$ in any group. Group EXN received preexposure to saccharin prior to testing by first receiving saccharin unpaired with $\mathrm{LiCl}$ during the conditioning phase. That group then received saccharin amounts during extinction that were yoked to Group 9N's saccharin consumption in that phase. Group EXN is similar to a latent inhibition control, for which saccharin preference would be expected to be weaker than that in a condition in which saccharin is a conditioned inhibitor (e.g., in the group of greatest interest, $9 \mathrm{~N}$ ). We were concerned that a new fluid stimulus introduced for the first time during testing could produce neophobia (see, e.g., Garcia, 1989), and so Groups 9N, 3N, and EXN each received three saline exposures in the pretraining phase. Saline was therefore equally familiar in these groups at the time of testing. If conditioned inhibition to saccharin accrues with nine extinction trials, Group 9N should have a stronger saccharin preference than does Group EXN.

In addition to these modifications, we included a control group (Group CI), compared with which Group 9N was expected to have a strong saccharin preference during testing. Group CI received the same treatment with saccharin as Group EXN, including yoking to Group 9N during extinction; thus, saccharin should be a latent inhibitor in Group CI as well as in Group EXN. But Group CI also received an $A+/ A X$ - pretreatment in which $X$ was saline; this was intended ultimately to enhance saline preference and, therefore, reduce relative saccharin preference. We closely followed the A+/AX - training procedure used by Best (1975; Best et al., 1985). At the time of testing, saccharin should be a latent inhibitor, and 
saline might be a conditioned inhibitor, in Group CI. Uncertainty remains about whether Best's procedure using CTA actually yields inhibition (see Delamater et al., 1986). However, we were less interested in obtaining conditioned inhibition to saline in Group CI than we were in simply using the A+/AX - procedure to establish, prior to testing, a strong preference for saline in Group $\mathrm{CI}$, as compared with the other groups. Given this, we thought it reasonable to expect Group CI to have the weakest saccharin preference among the groups during the saccharin-versus-saline preference test.

\section{Method}

Subjects and Apparatus. The subjects were $24 \mathrm{Wistar}$ rats bred at CSUF (12 female and 12 male). They were approximately 200 days old and ranged in weight from 250 to $350 \mathrm{~g}$ (females) and from 400 to $525 \mathrm{~g}$ (males) at the start of the experiment. Prior to this experiment, the rats had participated in an appetitive conditioning experiment in which they received presentations of a tone and food pellets. The rats were assigned to groups in this experiment orthogonally to groups in the earlier experiment, balancing by sex. The maintenance conditions and apparatus were the same as those in Experiment 4.

Proced ure. The basic drinking session procedures were the same as those in the previous experiments. Only the first drinking session of each day will be described. On the first 9 days of the experiment, all the rats received water, using the same schedule as that in Experiment 4. The rats were then assigned to Groups $9 \mathrm{~N}, 3 \mathrm{~N}, \mathrm{CI}$, and $\operatorname{EXN}(n \mathrm{~s}=8)$, matched on water intake and balanced on their left/right consumption.

The next 18 days constituted a pretraining phase prior to the groups' treatments with saccharin. In this phase, each group received some exposure to saline, the comparison fluid used subsequently in testing. Each rat in Group CI received eight saline exposures in the drinking box, intermixed with eight exposures to the box with no fluid available, in the sequence $\mathrm{A}+\mathrm{A}+\mathrm{R}, \mathrm{A}+, \mathrm{A}+\mathrm{R}$, $\mathrm{AX}-, \mathrm{A}+, \mathrm{AX}-, \mathrm{AX}-, \mathrm{A}+, \mathrm{AX}-, \mathrm{AX}-, \mathrm{AX}-, \mathrm{A}+, \mathrm{AX}-, \mathrm{A}+$, $\mathrm{AX}-$, where $\mathrm{A}$ indicates the drinking box apparatus, a plus indicates a $1 \%$ body weight, $0.15-\mathrm{m} \mathrm{LiCl}$ injection (following Best, 1975; Best et al., 1985), X indicates saline, and $\mathrm{R}$ indicates a recovery day. A+trials did not involve water or any other fluid in the drinking boxes but were followed $90 \mathrm{~min}$ later by a 15 -min waterdrinking session in the colony room. During the first 15 of these days, Groups $9 \mathrm{~N}, 3 \mathrm{~N}$, and EXN received water in the colony room. To reduce novelty effects of, and equate familiarity with, saline during testing, each of those groups received saline only (no $\mathrm{LiCl}$ ) on each of the final 3 days of this phase. For all the groups, the same number of days elapsed between the last saline exposures and testing.

The conditioning phase involved 2 days during which Groups $9 \mathrm{~N}$ and $3 \mathrm{~N}$ received saccharin followed by $0.3 \mathrm{M} \mathrm{LiCl}$ and Groups CI and $\mathrm{EXN}$ received saccharin and $0.3 \mathrm{M} \mathrm{LiCl}$ unpaired. On the 1 st day, all the groups were in the boxes for $15 \mathrm{~min}$, but no fluids were available. Groups $\mathrm{CI}$ and $\mathrm{EXN}$ received an $\mathrm{LiCl}$ injection after that $15-$ min period. On the 2 nd day, Groups $9 \mathrm{~N}$ and $3 \mathrm{~N}$ received saccharin and $\mathrm{LiCl}$; Groups $\mathrm{CI}$ and $\mathrm{EXN}$ received only saccharin. The day after the conditioning phase was a recovery day for all the groups. After the recovery day, Groups $9 \mathrm{~N}$ and $3 \mathrm{~N}$ received extinction, using the same procedures as those in Experiment 4. For each day during the extinction phase, saccharin consumption in Groups $\mathrm{CI}$ and EXN was yoked to that of Group $9 \mathrm{~N}$ by giving each of the rats in Groups CI and EXN the average saccharin volume consumed by the rats in Group $9 \mathrm{~N}$ on that day.

Conditioning and extinction was delayed for Group $3 \mathrm{~N}$ so that the extinction phase would end on the same day for all groups. Each group received the schedule of two drinks per day for the same total number of days prior to testing, and all the groups were tested on the same days. For all conditioning and extinction drinking sessions, each group received the drinking tube placed in the center hole of the box lid. Using the same criteria as before, we identified 3 rats from Group $9 \mathrm{~N}$ and 4 from Group $3 \mathrm{~N}$ that failed to show evidence of extinction. One rat from Group CI died during pretraining. The data from those rats were eliminated from the study (the resulting $n \mathrm{~s}=5,4,7$, and 8 , for Groups $9 \mathrm{~N}, 3 \mathrm{~N}, \mathrm{CI}$, and EXN, respectively). Eight days of testing began on the day following the end of extinction. All the groups received the same test procedure as that used in Experiment 4, except that saline was used instead of water.

\section{Results and Discussion}

There were no effects of the counterbalancing factors; therefore, analyses including those factors will not be reported. An ANOVA comparing initial saline consumption revealed that the groups did not differ $[F(3,20)<1]$. Saline consumption on the last 3 days of pretraining averaged 12.7, 15.1, and $14.3 \mathrm{ml}$ for Groups $9 \mathrm{~N}, 3 \mathrm{~N}$, and EXN, respectively. Over the 18-day pretraining phase, saline consumption on $\mathrm{AX}$ - days increased in Group CI from a mean of $14.6 \mathrm{ml}$ on the first 3 days to a mean of $19.7 \mathrm{ml}$ on the last $3[F(1,6)=11.77]$.

Saccharin consumption during conditioning averaged $12.6,13.5,13.5$, and $16.6 \mathrm{ml}$ for Groups $9 \mathrm{~N}, 3 \mathrm{~N}, \mathrm{EXN}$, and CI, respectively. A group ANOVA revealed no differences among the groups $[F(3,20)<1.64, p>.21]$. Saccharin consumption on the 1st day of extinction averaged $1.0 \mathrm{ml}$ for all the groups (Groups CI and EXN were yoked to Group $9 \mathrm{~N}$ during extinction). A trial $\times$ group ANOVA comparing consumption on the first trial of extinction with that of conditioning for Groups $9 \mathrm{~N}$ and $3 \mathrm{~N}$ revealed a trial effect $[F(1,7)=111.00]$ but no group effect or interaction $\left(F_{\mathrm{S}}<1\right)$. These groups did not differ during the first three extinction trials [Group $3 \mathrm{~N}$ received three extinction trials; $F(1,7)=2.93, p>$.13]. Consumption increased in Group 3N over those trials $[F(2,14)=25.41]$; there was no trial $\times$ group interaction $[F(2,14)=1.56, p>.24]$. Saccharin consumption on the third trial of the phase averaged 5.5 and $4.3 \mathrm{ml}$ for Groups $9 \mathrm{~N}$ and $3 \mathrm{~N}$, respectively. An ANOVA comparing those means revealed no difference $[F(1,7)=1.33, p>$ .28]. On the last trial of the extinction phase (Trial 9 for Group 9N, on which consumption averaged $13.2 \mathrm{ml}$ ), Group 3N differed from Group 9N $[F(1,7)>14.91]$. Groups 9N, CI, and EXN did not differ at any point during the extinction phase $\left(F_{\mathrm{S}}<1\right)$.

Figure 6 shows the 4 two-trial blocks of the two-bottle preference test comparing saccharin and saline consumption in all the groups. A block $\times$ group ANOVA on those data revealed an effect of group $[F(3,20)=8.41]$ and of block $[F(3,60)=5.77]$ and an interaction $[F(9,60)=$ 2.16]. Comparisons at each block revealed that Group $3 \mathrm{~N}$ had a weaker preference for saccharin, as compared with each of the other groups on the first three blocks [smallest $F(1,20)>5.53$ ] and relative to Groups EXN and CI on the last block [smallest $F(1,20)>4.87$ ]. Group $3 \mathrm{~N}$ did not differ from Group 9N on the last block $[F(1,20)=$ $4.28, p=.052]$. At no point in testing did Group $9 \mathrm{~N}$ differ from Group CI $(F<1)$. On the first block, Group EXN 


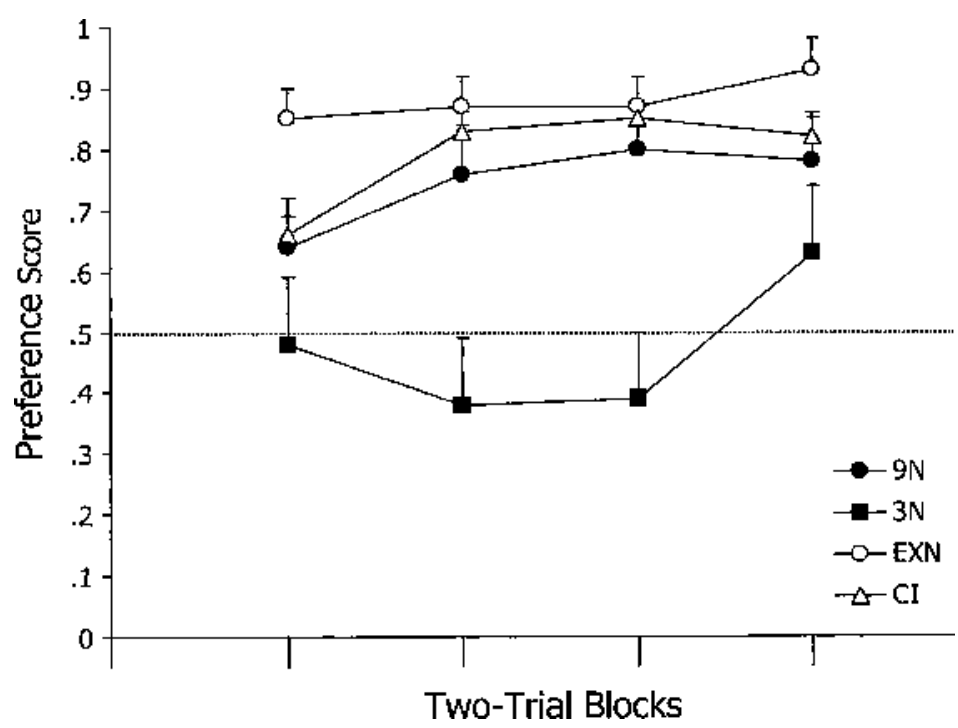

Figure 6. Group mean preference scores (saccharin/saccharin + saline) on the 4 two-trial blocks of the preference test in Experiment 5.

had a greater saccharin preference than did the other groups [smallest $F(1,20)=11.04]$. On the second and third blocks, Groups EXN and CI did not differ $[F(1,20)<$ $3.22, p>.08]$. On the fourth block, Group EXN had a stronger saccharin preference than did Groups $9 \mathrm{~N}$ and $3 \mathrm{~N}$ [smallest $F(1,20)=5.71$ ] but did not differ from Group CI $(F<1)$. Across all test blocks, Group 3N preferred saccharin less than did each of the other groups [smallest $F(1,20)=9.56$ ], and Groups 9N, CI, and EXN did not differ $[F(1,20)<2.93, p>.10]$. Also, Groups 9N, $\mathrm{CI}$, and EXN had saccharin preference scores that were significantly above a hypothetical population mean of .5 (smallest $t=7.40$ ), indicating t hat each of those groups preferred saccharin over saline during testing. Group $3 \mathrm{~N}$ did not differ from a hypothetical population mean of .5 $[t(3)<1.07]$. Overall consumption during testing (saccharin plus saline) averaged 15.6, 16.3,20.2, and $18.2 \mathrm{ml}$ for Groups $9 \mathrm{~N}, 3 \mathrm{~N}, \mathrm{EXN}$, and CI, respectively, and did not differ significantly among the groups $[F(3,20)=3.00$, $p=.055]$.

As in Experiment 4, nine extinction trials resulted in a greater saccharin preference than did three trials. The result is most consistent with the view that more extinction produces stronger latent inhibition. In contrast with Experiment 4, Group 9N exhibited an absolute preference for saccharin, indicating greater approach to saccharin. According to some theorists, this could be viewed as evidence of conditioned inhibition (e.g., Hearst \& Franklin, 1977; Wasserman et al., 1974). However, the only difference between Group $9 \mathrm{~N}$ in this experiment and Group 9 in Experiment 4 (which did not exhibit an absolute preference for saccharin) is the test comparison fluid (saline here, water in Experiment 4). It is rather unlikely that changing the comparison fluid to saline could create conditioned inhibition in Group 9N. Furthermore, there was no evidence that Group 9N's preference for saccharin constituted conditioned inhibition when compared with the controls. Group $9 \mathrm{~N}$ never had a greater saccharin preference than did the latent inhibition control (Group EXN), which received no conditioning and saccharin exposure yoked to Group 9N. In addition, Group CI was expected to have the weakest preference for saccharin (and the strongest preference for the comparison fluid, saline), relative to Groups $9 \mathrm{~N}$ and EXN. It is especially interesting, therefore, that Group 9N never preferred saccharin more than did Group CI. The emergence of an absolute saccharin preference in Group 9N is most likely due to the use of saline rather than water as the comparison test fluid, rather than to the development of conditioned inhibition to saccharin during extinction.

On the basis of Best's (1975; Best et al., 1985) work on conditioned inhibition, Group CI's weak saline drinking was unexpected. That group's saccharin preference might seem less surprising, however, considering that experience with an initial safe flavor can promote consumption of a second flavor (see, e.g., Bennett, Tremain, \& Mackintosh, 1996). Saccharin was consumed after saline in this experiment. However, no established theory parsimoniously predicts that mere consumption of one safe flavor should generate conditioned inhibition in the second flavor. If conditioned inhibition after nine extinction trials could be shown with the preference test, at minimum Group 9N should have had a greater saccharin preference than did Group CI; it did not. This observation, along with the failure to find greater saccharin preference in Group 9N than in Group EXN and the results of Experiment 2, creates an accumulation of evidence that is inconsistent with the view that conditioned inhibition develops during extinction of CTA.

This experiment was not designed to assess conditioned inhibition to saline in Group CI. Nevertheless, 
that group was expected to have had the strongest saline preference during the test, as Best's (1975; Best et al., 1985) reports suggest. Instead, that group had a clear preference for saccharin over saline, and its saccharin preference was equal to, or stronger than, that in the other groups. This could be viewed as a weakness of the preference test. However, this limitation does not weaken our objective of having an especially conservative control procedure for saccharin preference. It is worth noting, however, that although the present experiments were not intended to assess Group CI for conditioned inhibition to saline, the results provide no evidence contrary to Delamater et al.'s (1986) report, which questions the effectiveness of the $\mathrm{A}+/ \mathrm{AX}-$ procedure for producing conditioned inhibition with CTA procedures.

\section{GENERAL DISCUSSION}

The main objective of this study was to directly compare the effect of nine or three extinction trials following CTA training, using different testing procedures. Three different tests for inhibition were used after the same extinction procedures. In each experiment, there was less of an aversion to, or relatively greater preference for, saccharin after nine extinction trials. The pattern of results indicates that a form of inhibition developed more strongly after nine extinction trials. With the present procedures, we found no evidence of inhibition after only three extinction trials. The inhibition finding after nine trials is consistent with findings from previous retardation tests (e.g., Calton et al., 1996; Danguir \& Nicolaidis, 1977; Hart et al., 1995, Experiment 2; Schachtman et al., 2000). Experiment 2's summation test result, however, suggests that positive summation test results obtained after extinction in CTA are due to generalization decrement (see also Aguado et al., 2001). The patterns of data from that experiment and from the preference tests suggest that extended extinction results in latent inhibition, rather than in conditioned inhibition. In Experiment 2, unpaired and yoked controls passed a summation test, suggesting that extensively extinguished flavor aversions yield flavors that pass summation tests because of generalization decrement. This conclusion is supported by the preference test findings from Experiment 4 and, particularly, by those from Experiment 5, which indicated that extensively extinguishing a flavor (saccharin) aversion did not result in a greater flavor preference for, or approach to, that flavor, in comparison with unpaired yoked control groups that had experience with the test comparison flavor (saline) that was designed to differentially discourage saccharin consumption (Groups EXN and CI).

The greater preference for saccharin found in Groups $9 \mathrm{~N}, \mathrm{EXN}$, and CI could have been influenced by a natural preexisting preference for saccharin over saline. We collected pilot data on natural consumption tendency with naive rats other than those used in the experiments reported here. With the procedures and parameters used in these experiments, there was no evidence for a pre- existing tendency; that is, consumption of saccharin and saline was statistically similar $(F<1)$. Still, if the rats in Experiments 4 and 5 had an undetected natural tendency to prefer saccharin, that would further suggest that any saccharin preference observed on the tests could not readily be interpreted as evidence of conditioned inhibition. Interestingly, with the information from the control conditions of the present experiments, consumption volumes and preference scores reported in other two-bottle tests (e.g., Best, 1975; Best et al., 1985) may have reflected relative drinking preferences, rather than conditioned inhibition (e.g., compare Best et al., 1985, Experiment 1, with the present Experiment 4). Group 3N may have failed to show a preference for saccharin over saline because of residual aversion to saccharin, remaining after only three extinction trials. Thus, the overall pattern of results in these experiments is more parsimoniously explained by the development of latent inhibition during extensive extinction.

The present experiments offer several advantages over previous ones that have tested for inhibition in CTA. The between-subjects designs of the summation tests (Experiments 1 and 2) eliminated the chance of sequence effects that could occur with compound and element testing when some within-subjects designs are used (e.g., Aguado et al., 2001). Experiment 2 equated exposure to saccharin among the groups throughout the experiment. The equated exposure controlled for familiarity and possible neophobia effects. Also, the unpairing control procedure used in Experiment 2 may be viewed as an especially appropriate control for conditioned inhibition, as compared with the controls previously employed in CTA summation test experiments that have investigated either the effects of extinction (cf. Aguado et al., 2001; Calton et al., 1996) or inhibition with other procedures (e.g., Espinet, Iraola, Bennett, \& Mackintosh, 1995). One advantage of the present retardation test (Experiment 3 ) is that retardation was demonstrated clearly during the reacquisition phase. Earlier retardation tests were compromised by group differences on the first trial of reconditioning (Aguado et al., 2001) or by showing effects only during the reextinction portion of the test, rather than during reconditioning (Calton et al., 1996; but see Hart et al., 1995, Experiment 3). To our knowledge, no other experiments that have assessed conditioned inhibition in CTA have these combined advantages.

The differences produced by three or nine extinction trials can be explained by considering the possible role of retroactive interference produced by extinction (e.g., Bouton, 1993; Spear, 1978; see also Nelson \& Bouton, 1997). Bouton's view, for example, would posit that the saccharin conditioning phase results in the storage of a conditioningmemory (saccharin-illness), whereas extinction results in the storage of a separate memory involving saccharin (saccharin-no-illness). With an increasing number of extinction trials, the memory resulting from extinction may more strongly interfere with retrieval of the conditioning memory (see, e.g., McGeoch \& McDonald, 1931; Slamecka, 1960). Stronger interference by the ex- 
tinction memory resulting from nine trials could have promoted greater consumption of saccharin alone or in combination with vinegar on the retardation and the summation tests, respectively. It could have also promoted greater saccharin preference after nine trials than after three.

An interference view handles the preference test results parsimoniously. It is not contradicted by the failure to observe an absolute preference for saccharin over water following nine extinction trials. It is not incompatible with the greater saccharin preference in Group EX than in Group 9 (Experiment 4; although as was noted above, there may be other explanations for the difference between Groups 9 and EX in Experiment 4). Nor is it incompatible with the numerically greater saccharin preference in Groups EXN and CI than in Group 9N (Experiment 5). Because the control groups never received saccharin conditioning, there may have been little or no proactive interference with the effect of nonreinforced saccharin exposures in the extinction phase (see Bouton, 1993). If the other explanations are set aside, the findings of the absence and the presence of an absolute saccharin preference after nine extinction trials in Experiments 4 and 5 , respectively, might not seem to be readily accounted for by the interference view. But other considerations mitigate that possibility. The use of water as the comparison fluid in Experiment 4 may have led to overall lower saccharin preference, since water is typically safe and highly familiar. Indeed, a comparison of Figures 4 and 5 indicates that there was a numerically weaker overall saccharin preference in all the rats in Experiment 4, as compared with Experiment 5. As was mentioned before, the difference was likely due to the test comparison fluid (water in Experiment 4, saline in Experiment 5). In addition to the difference between Groups 9 and 9N, a nearly identical difference exists between Groups 3 and $3 \mathrm{~N}$. In Experiment 4, Group 3 had a weaker preference for saccharin; in Experiment 5, Group 3N had no preference. A theory would not be expected to explain such between-experiment variability. Furthermore, in its present form, the interference view predicts group differences in the extent of interference between memories involving saccharin, not those involving the comparison test fluid.

Our findings do not directly challenge the validity of preference tests in studies of CTA. The preference test results were analogous to results from the summation and retardation tests in showing consistent differences between three and nine extinction trials. However, the results from Experiment 5 do constitute a challenge to the usefulness of preference tests in the study of conditioned inhibition, because they indicate that approach to a fluid is not unambiguously indicative of conditioned inhibition (cf. Hearst \& Franklin, 1977; Wasserman et al., 1974). Furthermore, although studying the $\mathrm{A}+/ \mathrm{AX}-$ procedure was not an objective of Experiment 5, the comparison of Group CI with the other groups questions the effectiveness of the A+/AX - procedure for producing conditioned inhibition with CTA (see Delamater et al., 1986), and/or it questions the sensitivity of the preference test- ing technique to detect conditioned inhibition with the stimuli and A+/AX - procedure used here. Unpaired/ latent inhibition and yoked controls should be especially useful in preference test experiments to assess the kind of learning the $\mathrm{A}+/ \mathrm{AX}$ - procedure may produce. The experiments by Best (1975; Best et al., 1985) did not use such controls. (Note, however, that the stimuli used in those experiments were not identical to those used here or those used by Delamater et al., 1986.)

The differences shown here within each experiment following three or nine extinction trials are important in helping to clarify other findings obtained after extinction with CTA. In several studies testing postextinction aversion recovery effects with CTA, the aversion seems most weak when tested after more than three extinction trials but is stronger when tested after three or fewer trials. For example, reinstatement has been shown following three extinction trials (Schachtman et al., 1985; see also Schachtman et al., 1992), but not following five or more such trials (Bouton, 1982; Schachtman et al., 1985). Spontaneous recovery has been shown after three extinction trials (e.g., Brooks et al., 1999; Rosas \& Bouton, 1996, Experiments 1-3; cf. Kraemer \& Spear, 1992), but not after eight trials (Rosas \& Bouton, 1996, Experiment 4; see also Hart et al., 1995; Schachtman et al., 1985). The renewal effect has been shown after three trials (Rosas \& Bouton, 1997); it has not been assessed after more than three extinction trials within the same experiment. Slow reacquisition has been shown after eight or nine extinction trials, but not after only three (Calton et al., 1996; Danguir \& Nicolaidis, 1977; Hart et al., 1995; Schachtman et al., 2000).

When postextinction CR recovery effects have been shown with CTA studies, they are not numerically large, as compared with those often shown with other conditioning methods (e.g., Brooks et al., 1999; Rosas \& Bouton, 1996, 1997; Schachtman et al., 1985). This could be due to several factors, including, but not limited to, the extent of conditioning, US magnitude in conditioning, CS duration, retention interval duration, degree of temporal or physical context changes after extinction (e.g., in studies of spontaneous recovery or renewal, respectively), or extent of exposure to and/or magnitude of the US prior to testing (in studies of reinstatement). These factors deserve more extensive empirical study. In addition to a possible role for those factors, the present results suggest that one other factor at play, at least with CTA, is that extended extinction can produce latent inhibition that interferes with conditioning. Less extensive extinction produces weak or no latent inhibition. Compared with other conditioning methods, latent inhibition with CTA may develop after conditioning with relatively few, merely nonreinforced trials (e.g., Aguado, Symonds, \& Hall, 1994). This might explain the modest CR recovery effects found in some experiments that have manipulated retention interval, context, or US exposure after no more than three extinction trials, as well as the failures in other experiments to demonstrate those effects after more than three trials. Future research should di- 
rectly compare different numbers of extinction trials to assess whether time, context, and US exposure manipulations yield CR recovery only after a relatively small number of (e.g., three) extinction trials.

\section{REFERENCES}

Aguado, L., De Brugada, I., \& Hall, G. (2001). Tests for inhibition after extinction of a conditioned stimulus in the flavour aversion procedure. Quarterly Journal of Experimental Psychology, 54B, 201217.

Aguado, L., Symonds, M., \& Hall, G. (1994). Interval between preexposure and test determines the magnitude of latent inhibition: Implications for an interference account. Animal Learning \& Behavior, 22, 188-194.

Ayers, J. J. B., Philbin, D., Cassidy, S., Bellino, L., \& Redlinger, E. (1992). Some parameters of latent inhibition. Learning \& Motivation, 23, 269-287.

Bennett, C. H., Tremain, M., \& Mackintosh, N. J. (1996). Facilitation and retardation of flavour aversion conditioning following prior exposure to the CS. Quarterly Journal of Experimental Psychology, 49B, 220-230.

BEST, M. R. (1975). Conditioned and latent inhibition in taste-aversion learning: Clarifying the role of learned safety. Journal of Experimental Psychology: Animal Behavior Processes, 1, 97-113.

Best, M. R., Dunn, D. P., Batson, J. D., Meachum, C. L., \& Nash, S. M. (1985). Extinguishing conditioned inhibition in flavour-aversion learning: Effects of repeated testing and extinction of the excitatory element. Quarterly Journal of Experimental Psychology, 37B, 359378.

Bevins, R. A., Jensen, H. C., Hinze, T. S., \& Besheer, J. (1999). Taste quality and extinction of a conditioned taste aversion in rats. Animal Learning \& Behavior, 27, 358-366.

Bouton, M. E. (1982). Lack of reinstatement of an extinguished taste aversion. Animal Learning \& Behavior, 10, 233-241.

Bouton, M. E. (1986). Slow reacquisition following the extinction of conditioned suppression. Learning \& Motivation, 17, 1-15.

Bouton, M. E. (1993). Context, time, and memory retrieval in the interference paradigms of Pavlovian learning. Psychological Bulletin, 114, 80-99.

Brooks, D. C., Palmatier, M. I., Garcia, E. O., \& Johnson, J. L. (1999). An extinction cue reduces spontaneous recovery of a conditioned taste aversion. Animal Learning \& Behavior, 27, 77-88.

Calton, J. L., Mitchell, K. G., \& Schachtman, T. R. (1996). Conditioned inhibition produced by extinction of a conditioned stimulus. Learning \& Motivation, 27, 335-361.

DANGUIR, J., \& NICOLAIDIS, S. (1977). Lack of reacquisition in learned taste aversions. Animal Learning \& Behavior, 5, 395-397.

Delamater, A. R., Krause, J. M., Marlin, S., \& LoLordo, V. M. (1986). Conditioned inhibition in taste aversion learning: Testing methodology and empirical status. Animal Learning \& Behavior, 14, 6-14.

Espinet, A. Iraola, J. A., Bennett, C. H., \& Mackintosh, N. J. (1995). Inhibitory associations between neutral stimuli in flavoraversion conditioning. Animal Learning \& Behavior, 23, 361-368.

GARCIA, J. (1989). Food for Tolman: Cognition and cathexis in concert. In T. Archer \& L. G. Nilsson (Eds.), Aversion, avoidance, and anxiety: Perspectives on aversively motivated behavior (pp. 45-85). Hillsdale, NJ: Erlbaum.

Hart, J. A., Bourne, M. J., \& Schachtman, T. R. (1995). Slow reacquisition of a conditioned taste aversion. Animal Learning \& Behavior, 23, 297-303.

Hearst, E., \& Franklin, S. R. (1977). Positive and negative relations between a signal and food: Approach-withdrawal behavior to the signal. Journal of Experimental Psychology: Animal Behavior Processes, 3, 37-52.

Howell, D. C. (1987). Statistical methods for psychology (2nd ed.). Boston: PWS-Kent.
Hull, C. L. (1943). Principles of behavior. New York: Appleton-CenturyCrofts.

KonORSKI, J. (1948). Conditioned reflexes and neuron organization. Cambridge: Cambridge University Press.

Kraemer, P. J., \& Spear, N. E. (1992). The effect of nonreinforced stimulus exposure on the strength of a conditioned taste aversion as a function of retention interval: Do latent inhibition and extinction involve a shared process? Animal Learning \& Behavior, 20, 1-7.

LoLordo, V. M., \& FAIRLESS, J. L. (1985). Pavlovian conditioned inhibition: The literature since 1969. In R. R. Miller \& N. E. Spear (Eds.), Information processing in animals: Conditioned inhibition (pp. 149). Hillsdale, NJ: Erlbaum.

Lubow, R. E. (1989). Latent inhibition and conditioned attention theory. New York: Cambridge University Press.

Mackintosh, N. J. (1983). Conditioning and associative learning. New York: Oxford University Press.

McGeoch, J. A., \& McDonald, W. T. (1931). Meaningful relation and retroactive inhibition. American Journal of Psychology, 43, 579-588.

Miller, R. R., Kasprow, W. J., \& Schachtman, T. R. (1986). Retrieval variability: Sources and consequences. American Journal of Psychology, 99, 145-218.

Nelson, J. B., \& Bouton, M. E. (1997). The effects of a context switch following serial and simultaneous feature-negative discriminations Learning \& Motivation, 28, 56-84.

Pavlov, I. P. (1927). Conditioned reflexes (G. V. Anrep, Trans.). London: Oxford University Press.

Pearce, J. M., \& Hall, G. (1980). A model for Pavlovian learning: Variations in the effectiveness of conditioned but not of unconditioned stimuli. Psychological Review, 87, 532-552.

Rescorla, R. A. (1969). Pavlovian conditioned inhibition. Psychological Bulletin, 72, 77-94.

Rescorla, R. A. (1979). Conditioned inhibition and extinction. In A. Dickinson \& R. A. Boakes (Eds.), Mechanisms of learning and motivation: A memorial volume to Jerzy Konorski (pp. 83-110). Hillsdale, NJ: Erlbaum.

Rosas, J. M., \& Bouton, M. E. (1996). Spontaneous recovery after extinction of a conditioned taste aversion. Animal Learning \& Behavior, 24, 341-348.

Rosas, J. M., \& Bouton, M. E. (1997). Renewal of a conditioned taste aversion upon return to the conditioning context after extinction in another one. Learning \& Motivation, 28, 216-229.

Savastano, H. I., Cole, R. P., Barnet, R. C., \& Miller, R. R. (1999). Reconsidering conditioned inhibition. Learning \& Motivation, 30, 101-127.

Schachtman, T. R., Brown, A. M., \& Miller, R. R. (1985). Reinstatement-induced recovery of a taste- $\mathrm{LiCl}$ association following extinction. Animal Learning \& Behavior, 13, 223-227.

Schachtman, T. R., Gustavson, K. K., Chelonis, J. J., \& Bourne, M. J. (1992). Effects of US reinstatement on the potential of an extinguished CS to attenuate manifest learning about another CS. Learning \& Motivation, 23, 250-268.

Schachtman, T. R. Threlkeld, R., \& Meyer, K. (2000). Retention of conditioned inhibition produced by extinction. Learning \& Motivation, 31, 283-300.

SlamecKa, N. J. (1960). Retroactive inhibition of connected discourse as a function of practice level. Journal of Experimental Psychology, 59, 104-108.

SPEAR, N. E. (1978). The processing of memories: Forgetting and retention. Hillsdale, NJ: Erlbaum.

Wasserman, E. A., Franklin, S. R., \& Hearst, E. (1974). Pavlovian appetitive contingencies and approach vs. withdrawal to conditioned stimuli in pigeons. Journal of Comparative \& Physiological Psychology, 86, 616-627.

Williams, D. A., Overmier, J. B., \& LoLordo, V. M. (1992). A reevaluation of Rescorla's early dictums about Pavlovian conditioned inhibition. Psychological Bulletin, 111, 275-290.

(Manuscript received January 10,2002; revision accepted for publication December 15, 2002.) 